\title{
Mapping of clay soils exposed to the shrinking - swelling phenomenon, with EO - 1 - Hyperion data in the region of Sidi - Chahmi, Algeria
}

\author{
Farid Rahal 1, ${ }^{*}$, Fatima - Zohra Baba - Hamed ${ }^{2}$, Mohamed Hadjel ${ }^{3}$ \\ ${ }^{1}$ Laboratory of Sciences - Technology and Process Engineering, Oran, Algeria \\ ${ }^{2}$ Civil engineering Department - University of Sciences and Technology of Oran, Oran, Algeria \\ ${ }^{3}$ Laboratory of Sciences, Technology and Process Engineering, Oran, Algeria
}

\section{ARTICLE INFO}

Article history:

Received 12 $2^{\text {th }}$ Aug. 2021

Revised 09th Nov. 2021

Accepted 30 $30^{\text {th }}$ Nov. 2021

\section{Keywords:}

Cartography.

Clay,

Hyperspectral image,

Shrinking - swelling.

\section{ABSTRACT}

Satellite images have a remarkable ability to help researchers map the distribution and detect the nature of the soil exposed on the earth's surface. The remote-sensing mapping of clayey soils makes it possible to determine their shrinking-swelling potentials. This approach is helpful in analyzing large areas where the traditional sampling approach with laboratory analysis is expensive. This high cost often leads to a limited number of samples and thus to a poor representation of a site with an underestimation of the presence of swelling soils. The Sidi - Chahmi area is representative of this type of soil. In addition, it is an area that undergoes the substantial urban sprawl of the city of Oran. The urbanization of this area is under the risk of clay-type soil movements, the identification of which by satellite imagery may help mitigate shrink-swell risk. E0-1-Hyperion hyperspectral images, whose effectiveness has already been proven for mapping clay minerals, were used to identify minerals such as illite, montmorillonite, and kaolinite in the Sidi - Chahmi area.

\section{Introduction}

Remote sensing has shown its potential as a complementary, faster, and less expensive technique, which can support traditional cartography and geotechnical investigation

\section{${ }^{*}$ Corresponding author}

E-mail: farid.rahal@univ - usto.dz

DOI: 10.46326/JMES.2021.62(6).01
(Yitagesu et al., 2009).

Bourguignon et al. (2007) used the ASTER space radiometer (Advanced Spaceborne Thermal Emission and Reflection Radiometer) to map clay minerals via the six spectral bands in its shortwave infrared range, in particular the wavelengths between $2.145 \mu \mathrm{m}$ and $2.43 \mu \mathrm{m}$.

Several studies on the mapping of swelling soils using remote sensing are reported in the literature of airborne Visible hyperspectral 
images/ Infrared Imaging Spectrometer (AVIRIS)/ Hyperspectral Mapper HyMap to identify and map swelling soils (Chabrillat et al., 2002).

The characterization of soils at risk makes it possible to provide real solutions for construction on clay soils. Indeed, the clay formations are most likely to experience the shrinking-swelling hazard.

Clay soils are all the more affected as their fine fraction is rich in certain clay minerals, mainly from the smectite family and certain interstratified illite - smectite type (Vincent et al., 2007).

In the event of urban sprawl, the total cost of claims related to the shrinking-swelling phenomenon of clay formations is known as an additional cost of about $20 \%$ compared to a limitation of the artificialized area (Gourdier et al., 2018). The region of Sidi - Chahmi is affected by this phenomenon because its clay soil shelters a significant part of Oran city's urban extension.

Indeed, the Oran agglomeration continues to expand eastwards (Bendraoua et al., 2011; Kadri et al., 2015), especially towards the commune of
Sidi - Chahmi. This extension was confirmed by studying a chronological series of satellite images covering the years 1984, 1995, 2005, and 2015 (Rahal et al., 2018).

This article aims to propose for Sidi - Chahmi region, a rapid mapping method from hyperspectral data to identify and locate clay soils with significant potential for shrinking - swelling.

Based on a geographic information system, this mapping of clay soils can be crossed with urbanization projects maps, thus allowing a design of new constructions adapted to the soil characteristics.

\section{Presentation of the Sidi - Chahmi region}

The agglomeration of Sidi - Chahmi was first a colonial village created in 1845 (Busson, 1898). It is a commune in Wilaya of Oran located in the northwest of Algeria. It is contiguous to the Oran agglomeration, of which it is subject to its significant influence (Figure 1).

From a simple hamlet of 2,376 inhabitants in 1966, this area reached 189,614 inhabitants in 2018 , with an exceptional annual growth rate of $31.75 \%$ between 2015 and 2018. Figure 2 shows

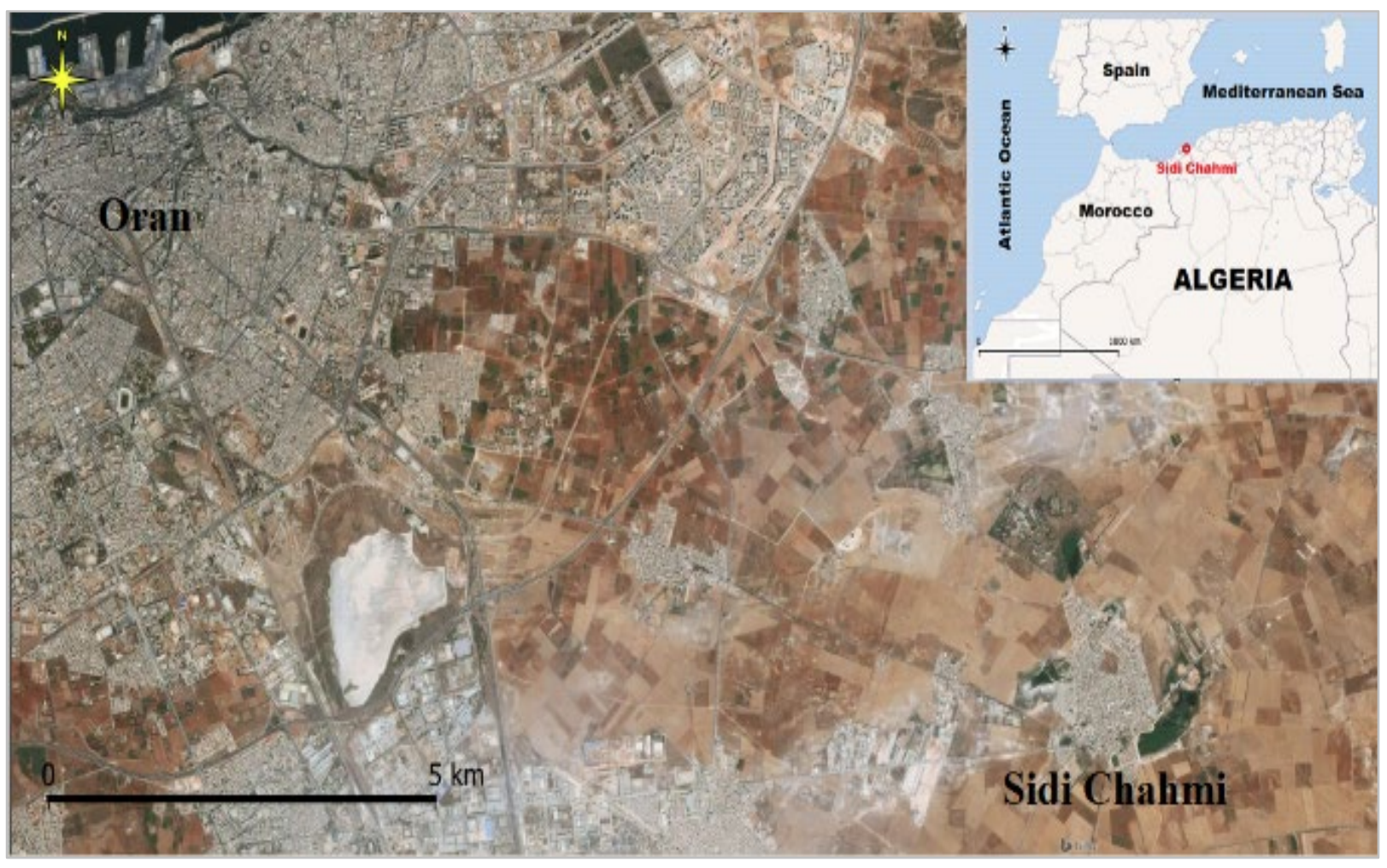

Figure 1. Geographic position of the Sidi - Chahmi region in Algeria. 
the evolution of the Sidi - Chahmi population.

This lightning growth allows it to reach the rank of suburban agglomeration in total contradiction with the orientations of the urban plan (Bendraoua et al., 2008). This demographic development is explained by the fact that Sidi Chahmi was among the privileged municipalities for the establishment of urban social housing (Said, 2005).

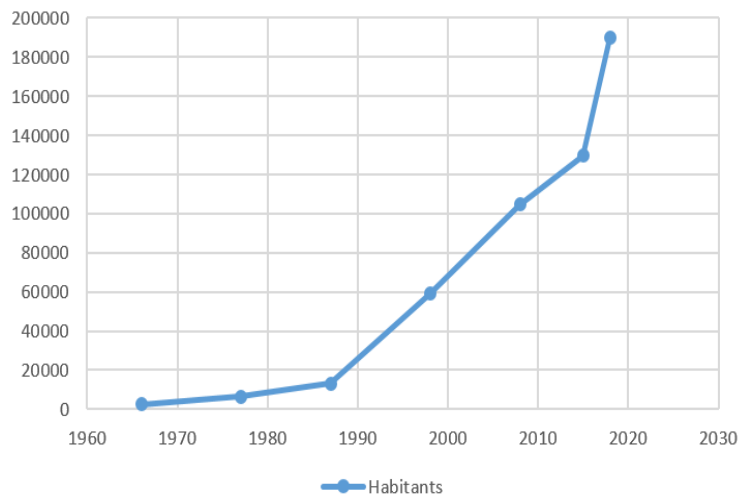

Figure 2. Geographic Demographic evolution of the commune of Sidi - Chahmi in Algeria.

(Sources : Ghomari, 2001 ; Rahal et al., 2018 ; ANIREF, 2018).

Damage to structures linked to soil swelling has been reported in the Sidi - Chahmi region due to the clayey nature of the soil (Hachichi et al., 1999; Hachichi et al., 2007). Indeed, soil analyzes have shown that it consists of two superimposed layers. The first comprises quaternary lacustrine clay with sandy and limestone parts. The second layer, underlying the first, is formed from more or less sandy Pliocene marl. The formations that cover the plateau are alluvial deposits made up of sometimes silty clays. (Bengraa et al., 2008). Figure 3 shows the geological composition of the Sidi - Chahmi area.

According to the classification of Williams and Donaldson (1980), the clay of Sidi - Chahmi has a very high swelling potential (Hachichi et al., 2009), hence the importance of identifying its location to avoid the risks induced by massive urbanization in this region.

X-ray diffractometric analysis shows that Sidi - Chahmi's clay consists of kaolinite, illite, Illite/montmorillonite interlayered, quartz, and calcite (Hachichi et al., 2007).

\section{Analysis of hyperspectral data from the Sidi - Chahmi region}

Remote sensing has the potential to provide detailed mineralogy of the earth's surface. At the beginning of the development of this technology, geological applications, and mineral exploration were among its most important uses.

Subsequently, there is the advent of multispectral and hyperspectral space sensors such as ASTER (Advanced Spaceborne Thermal Emission and Reflection Radiometer) and Hyper-

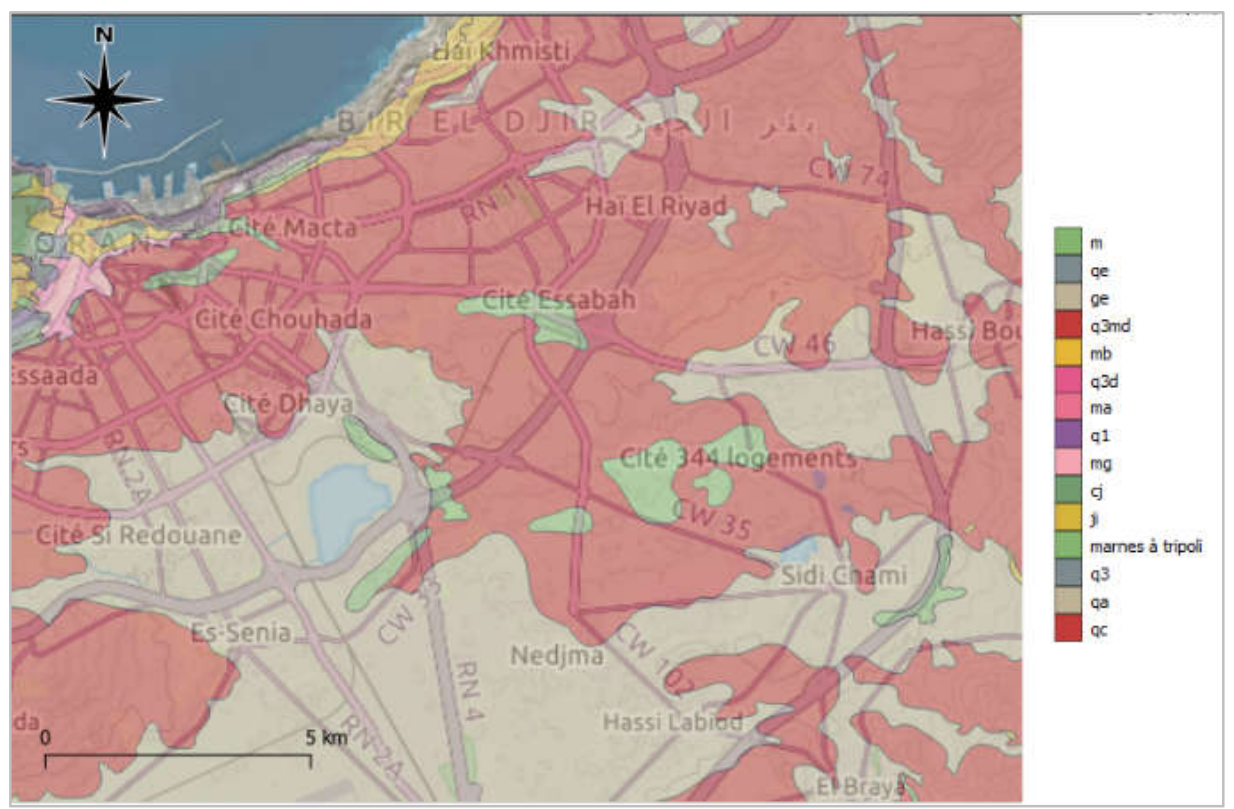

Figure 3 Geological composition of the Sidi - Chahmi area (Source: Baba Hamed et al., 2013). 
ion provided better quality data for mineral exploration (Zhang et al., 2007). These developments have enabled remote sensing to become an increasingly important tool for mineral exploration, particularly when little or no detailed topographic and geological maps are available and when access to the ground is difficult or sensitive (Perry, 2004).

Satellite data can help carry out more extensive mapping of surface soil properties in semi-arid contexts (Gasmi et al., 20019), which is the case for the Oran region (Bounoua et al., 2009) which includes Sidi - Chami area.

It has been clearly demonstrated that only hyperspectral imagery offers the possibility of identifying and quantifying the mineralogical composition of surfaces. This type of data is also essential in crisis management, such as shrinkingswelling of clays (Hyperspectral Synthesis Group, 2008).

The Hyperion sensor is one of the most important remote information sources for mapping the minerals present on the earth's surface (Zazi et al., 2017). In this study, a Hyperion image taken on $11 / 29 / 2016$ was used to identify clay minerals such as illite, kaolinite and montmorillonite, using Spectral Angle Mapper (SAM) classification and by matching the spectral signatures of the clay minerals from the spectral library of the Jet Propulsion Laboratory (JPL). Figure 4 shows the position of the hyperspectral image displayed in bands 29, 20 and 12, concern- ing the Sidi - Chahmi region.

Hyperion images have a spatial resolution of $30 \mathrm{~m}$ with a spectral range from $0.4 \mu \mathrm{m}$ to $2.5 \mu \mathrm{m}$. These images are made up of 242 bands, but not all of them can be used. It is then a question of eliminating the null bands and those presenting an excessive noise. The image used has been corrected at the atmospheric level using the atmospheric correction module QUAC (Quick Atmospheric Correction).

The image classification was carried out by the SAM (spectral angle mapper) method, which makes it possible to quickly map clayey soils by calculating the spectral similarity between the reflectance spectra of the image and the reflectance spectra of the targeted materials of the JPL spectral library.

This method has been successfully used for remote sensing of clay soils by Ghosh et al. (2016); El - Magd et al. (2015); Cheng et al. (2008) on ASTER multispectral images but also Hyperion hyperspectral images (Zazi et al., 2017; Bhattacharya et al., 2012; Yan - Hong et al., 2010).

The results of the SAM classification method are presented in Figure 5, indicating that the dominant minerals are illite in red, kaolinite in blue, and montmorillonite in yellow, thus consistent with the laboratory analyses carried out by Hachichi and al. (2007).

The results make it possible to identify the location of clay soils, in particular in the northern zone of Sidi - Chahmi. This region, not yet artificia-

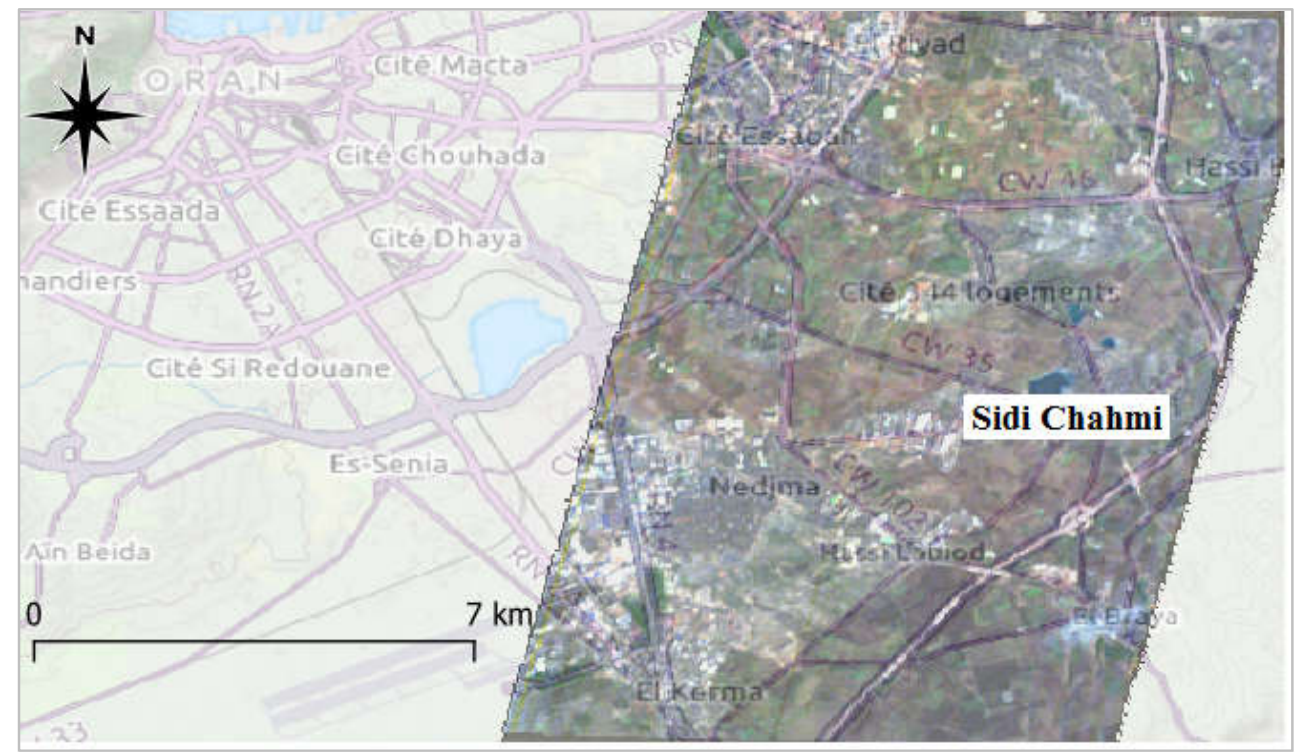

Figure 4. Hyperion image of 11/29/2016, displayed in bands 29, 20 and 12, of the Sidi - Chahmi region. 


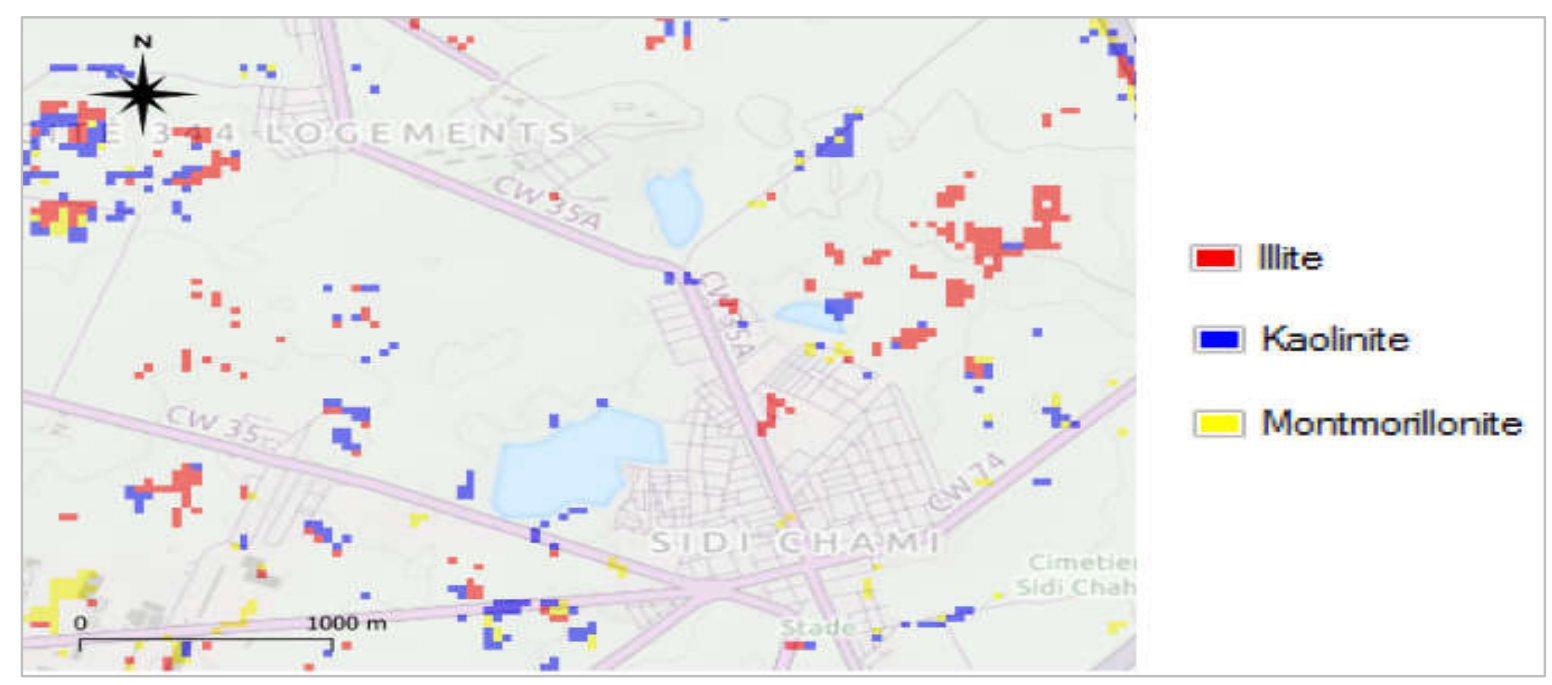

Figure 5. Classification of a Hyperion image of 11/29/2016 from the Sidi - Chahmi region using the SAM method.

lized, is likely to host the frantic urbanization of Oran city.

\section{Conclusion}

The Sidi - Chahmi region is characterized by vast bare and dry soil areas. The classification of Hyperion data has made it possible to locate and identify clayey soils with proven swelling potential. Hyperspectral images are favored over multispectral data whose spectral bands are too wide and too few to allow the identification and quantification of minerals (Groupe de Synthèse Hyperspectrale, 2008).

Damage to buildings can be avoided or mitigated if the soil properties are known, and their distribution is fairly well mapped before the start of any construction activity (Ramakrishnan et al., 2008).

Thus, the combination of the classification of clayey soils with urban cartography makes it possible to plan future extensions well and not to wait for the beginning of a construction project to realize that it is a clay soil susceptible to shrinking - swelling.

\section{Author contributions}

Farid Rahal - built up conception, data analysis and draft the article. Fatima - Zohra Baba - Hamed contributed to the methodology and Mohamed Hadjel author give a critical review for the final version to be submitted.

\section{References}

Aniref. (2018). Report on the Wilaya Of Oran. Agence Nationale d'Intermédiation et de Régulation Foncière.

Baba Hamed, F. Z., Rahal, D. D., Rahal, F. (2013). Seismic risk assessment of Algerian buildings in urban area. Journal of Civil Engineering and Management, 19(3), 348 - 363.

Bendraoua, F., Souiah, S. A. (2008). Quand les pouvoirs publics produisent de nouvelles marginalités urbaines: les recasés de Nedjma à Oran (Algérie). Autrepart, (1), 173 - 190.

Bendraoua, F., Bedidi, A., \& Cervelle, B. (2011). Dynamique spatio - temporelle de l'agglomération oranaise (Algérie) par télédétection et SIG. Revue du comité français de cartographie, (209), 103 - 113.

Bengraa, L., Hachichi, A., Benaissa. (2008). Stabilısatıon des argles gonflantes de la région d'Oran par ajout de sable. Actes du colloque international "Innovative Geotechnical Engineering, International Conference on Geotechnical Engineering" Hammamet, Tunisia.

Bhattacharya, S., Majumdar, T. J., Rajawat, A. S., Panigrahi, M. K., \& Das, P. R. (2012). Utilization of Hyperion data over Dongargarh, India, for mapping altered/weathered and clay minerals 
along with field spectral measurements. International journal of remote sensing, 33(17), 5438 - 5450.

Bounoua, L., Safia, A., Masek, J., Peters - Lidard, C., \& Imhoff, M. L. (2009). Impact of urban growth on surface climate: A case study in Oran, Algeria. Journal of applied meteorology and climatology, 48(2), 217 - 231.

Bourguignon, A., Delpont, G., Chevrel, S., \& Chabrillat, S. (2007). Detection and mapping of shrink-swell clays in SW France, using ASTER imagery. Geological Society, London, Special Publications, 283(1), 117 - 124.

Chabrillat, S., Goetz, A. F., Krosley, L., \& Olsen, H. $W$. (2002). Use of hyperspectral images in the identification and mapping of expansive clay soils and the role of spatial resolution. Remote sensing of Environment, 82(2 - 3), 431 - 445.

Cheng, B., Jiao, W., Wang, W., Zhang, X., Xiang, B., \& Liu, H. (2008, May). Information extraction based on SAM of ASTER image. In 2008 Congress on Image and Signal Processing, 3, 781-785). IEEE.

El - Magd, I. A., Mohy, H., \& Basta, F. (2015). Application of remote sensing for gold exploration in the Fawakhir area, Central Eastern Desert of Egypt. Arabian Journal of Geosciences, 8(6), 3523 - 3536.

Gasmi, A., Gomez, C., Lagacherie, P., \& Zouari, H. (2019). Surface soil clay content mapping at large scales using multispectral (VNIR-SWIR) ASTER data. International journal of remote sensing, 40(4), 1506 - 1533.

Ghomari, A. (2001). Genèse de la métropole oranaise: recomposition spatiale et dynamique sociale. Insaniyat. Revue algérienne d'anthropologie et de sciences sociales, (14 15), 83 - 97.

Ghosh, U. K., Naik, K. K., \& Kesari, M. P. (2016). Digital image processing of multispectral ASTER imagery for delineation of alteration and related clay minerals in Sakoli belt: Maharashtra-A case study. Journal of the Geological Society of India, 88(4), 464 - 470.
Gourdier, S., \& Plat, E. (2018). Impact du changement climatique sur la sinistralité due au retrait - gonflement des argiles.

Hachichi, A., \& Fleureau, J. M. (1999). Caractérisation et stabilisation de quelques sols gonflants d'Algérie. Revue française de géotechnique, (86), 37 - 51.

Hachichi, A., Bourokba, S., \& Fleureau, J. M. (2007). Stabilisation chimique de deux sols gonflants de la région d'Oran. Revue française de géotechnique, (118), 3 - 11.

Hachichi, A., Bourokba, S. A., Benaissa, A., Fleureau, J. M., Hattab, M., Taïbi, S. (2009). Etude des phénomènes retrait - gonflement et stabilisation des sols gonflants de la région d'Oran, Congrès Français de Mécanique.

Perry, S. L. (2004). Spaceborne and airborne remote sensing systems for mineral exploration - case histories using infrared spectroscopy. Infrared spectroscopy in geochemistry, exploration geochemistry, and remote sensing, 33, 227 - 240.

Rahal, F., Hadjou, Z., Blond, N., \& Aguejdad, R. (2018). Croissance urbaine, mobilité et émissions de polluants atmosphériques dans la région d'Oran, Algérie. Cybergeo: European Journal of Geography.

Ramakrishnan, D., \& Kusuma, K. N. (2008). Marine clays and its impact on the rapid urbanization developments: A case study of Mumbai area using EO - 1 - Hyperion data. Hyperspectral remote sensing and spectral signature applications, 53 - 64 .

Said, A. (2005). Le logement social urbain et la dynamique spatiale. Stratégie des acteurs décideurs à Oran (1990 - 2000). Insaniyat. Revue algérienne d'anthropologie et de sciences sociales, (29 - 30), 231 - 247.

Yitagesu, F. A., van der Meer, F., van der Werff, H., \& Zigterman, W. (2009). Quantifying engineering parameters of expansive soils from their reflectance spectra. Engineering geology, 105(3 - 4), 151 - 160.

Williams, A. A., \& Donaldson, G. W. (1980). Building on expansive soils in South Africa: 
1973 - 1980. In Expansive Soils, (834 - 844). ASCE.

Yan - Hong, L. I. U., Shao - Feng, L. I. U., Chuan, Z. H. A. N. G., \& Xiao - Yin, P. E. I. (2010). The Weight Information Extraction of Clay Minerals Based on Hyperion Data: A Case Study of Ganzhou Area, Jiangxi Province. Remote Sensing for Land \& Resources, 22(3), 26 - 30.

Zazi, L., Boutaleb, A., \& Guettouche, M. S. (2017). Identification and mapping of clay minerals in the region of Djebel Meni (Northwestern Algeria) using hyperspectral imaging, EO - 1 Hyperion sensor. Arabian Journal of Geosciences, 10(11), 252.

Zhang, X., \& Pazner, M. (2007). Comparison of lithologic mapping with ASTER, hyperion, and ETM data in the southeastern Chocolate Mountains, $\quad$ USA. Photogrammetric Engineering \& Remote Sensing, 73(5), 555 - 561. 